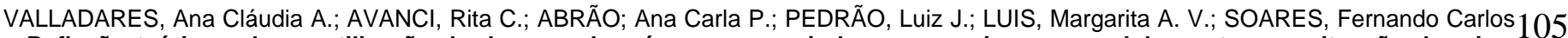
- Reflexão teórica sobre a utilização da dança e da máscara no sociodrama moreniano com adolescentes em situação de crise.

Revista Eletrônica de Enfermagem, v. 07, n. 01, p. 105 - 112, 2005. Disponível em www.fen.ufg.br/revista.htm

\title{
REFLEXÃO TEÓRICA SOBRE A UTILIZAÇÃO DA DANÇA E DA MÁSCARA NO SOCIODRAMA MORENIANO COM ADOLESCENTES EM SITUAÇÃO DE CRISE
}

\author{
THEORETICAL REFLECTION ABOUT THE USE OF THE DANCE AND OF THE MASK IN SOCIODRAMA \\ MORENIANO WITH ADOLESCENTS IN SITUATION OF CRISIS
}

\section{LA REFLEXIÓN TEÓRICA SOBRE EL USO DEL BAILE Y DE LA MÁSCARA EN SOCIODRAMA MORENIANO CON LOS ADOLESCENTES EN LA SITUACIÓN DE CRISIS}

\author{
Ana Cláudia A Valladares ${ }^{1}$ \\ Rita C Avanci ${ }^{2}$ \\ Ana Carla P Abrão ${ }^{2}$ \\ Luiz J Pedrão ${ }^{3}$ \\ Margarita A V Luis ${ }^{3}$ \\ Fernando Carlos Soares ${ }^{4}$
}

RESUMO: A adolescência é uma fase do desenvolvimento humano, um período evolutivo de transição entre a infância e a vida adulta. É um momento de definições de "identidade" sujeito à instabilidade psíquica. Este trabalho tem como objetivo propor uma reflexão sobre o sociodrama com o uso de confecção de máscaras e o uso da dança, bem como sua aplicação junto a alunos adolescentes em situação de crise, mais especificamente, aqueles recém ingressos no curso de graduação em Enfermagem de Universidades públicas. Para tanto, os autores realizaram uma busca em livros, dissertações, teses e artigos de revistas científicas. De posse do material, foi procedida a leitura; a seguir foram elaboradas as sínteses, descrições, reflexões e articulações entre os temas abordados. Tal busca confirmou que as atividades sociodramáticas, associadas à dança e à máscara, desenvolvem a expressão e a imaginação espontânea, descarregam tensões e ainda exteriorizam alegrias, temores e fantasias.

PALAVRAS CHAVES: Psicodrama; Psicologia do Adolescente; Saúde Mental.

ABSTRACT: Adolescence is a human being phase of development, evolutionary period of transition between childhood and adult life. This is a moment of personal "identity" definitions subject to psychic instability. This article has as objective to propose a discussion about the sociodrama with masks montagem and dance as applying strategy with adolescent students in crisis, closer with that ones recently admitted at Public Universities Nursing Colleges. Extensive searches were made in books, dissertations, theories and articles of scientific journals. After this, all bibliographies were read and then elaborated synthesis, descriptions, and interrelationships among the approached themes. The analysis confirmed that sociodramatic activities, associated to the dance and to the mask, develops the expression and spontaneous imagination, release tensions and even bring out joy, fears and fantasies.

KEY WORDS: Psychodrama; Adolescent Psychology; Mental Health.

RESUMEN: La adolescencia es una fase del desarrollo humano, e un período evolutivo de la transición entre la niñez y vida adulta. Éste es un momento de definiciones de la "identidad" personal e también de inestabilidad psíquica. Este artículo tiene como objetivo proponer una discusión sobre el sociodrama asociado a la confección de máscaras y danza como estrategia de trabajo con estudiantes adolescentes en crisis, recientemente admitidas en universidades públicas. Las búsquedas extensas fueron hechas en libros, disertaciones, teorías y artículos científicos. Después de esto, todas las bibliografías fueron leídas y entonces elaboradas las síntesis, las descripciones, y las correlaciones los temas acercados. El análisis confirmó que las actividades sociodramatica, asociadas a la danza y a la máscara, desarrollan la expresión y la imaginación espontánea, las tensiones del lanzamiento e incluso pone en evidencia alegría, miedos y fantasías.

PALABRAS-CLAVE: Psicodrama; Psicología del Adolescente; Salud Mental,

\section{INTRODUÇÃO}

Segundo a OPS e a OMS, a adolescência constitui-se num processo fundamental biológico de vivências orgânicas, no qual se aceleram o desenvolvimento cognitivo e a estruturação da personalidade, abrangendo a pré-adolescência (faixa etária de 10 a 14 anos) e a adolescência propriamente dita (dos 15 aos 19 anos). Segundo o paradigma biomédico, a adolescência tem sido descrita eminentemente de modo limitante, isto é, como uma fase do desenvolvimento humano, período evolutivo de transição entre a infância e a vida adulta. Esse processo ocorre na segunda década da vida, marcado pelas transformações biológicas da puberdade, estando relacionado à maturidade bio-psico-social (ABEN, 2001). 
VALLADARES, Ana Cláudia A.; AVANCI, Rita C.; ABRÃO; Ana Carla P.; PEDRÃO, Luiz J.; LUIS, Margarita A. V.; SOARES, Fernando Carlos106 - Reflexão teórica sobre a utilização da dança e da máscara no sociodrama moreniano com adolescentes em situação de crise. Revista Eletrônica de Enfermagem, v. 07, n. 01, p. 105 - 112, 2005. Disponível em www.fen.ufg.br/revista.htm

Tais transformações apresentam-se como cruciais na vida dos indivíduos, que identificam a adolescência como um período "crítico", momento de definições de "identidade" - sexual, profissional, de valores, e sujeito a uma instabilidade psíquica, muitas vezes tratada como patológica, ou até mesmo, dentro de um quadro típico de adolescência, como propõem alguns autores, recebem o nome de "Síndrome da Adolescência Normal" (ABERASTURY \& KNOBEL, 2000).

A influência da posição social do indivíduo é significativa num mesmo momento histórico, pois ela permite a exposição de padrões de comportamento e modos diferenciados de estruturação da adolescência (BECKER, 1994), uma vez que, ao buscarem as identidades pessoal e profissional, os adolescentes desejam ter um "referencial que dê sentido a seu existir". Esta disponibilidade do adolescente deve ser captada pelos profissionais de saúde no sentido de promoverem condutas comprometidas com a qualidade e vida e com as comunidades onde se inserem.

$\mathrm{Na}$ sociedade brasileira, a adolescência é tida como um fenômeno social que tem implicações políticas, jurídicas, culturais, existenciais, sexuais, psicológicas e biológicas, o que exige dos teóricos que tentam definir a adolescência compreensão da camada social constituinte do grupo, da faixa etária que ocupa, da tipicidade que pode apresentar e de quem a define como tal (RASPANTI, 2002).

O conceito moderno de adolescência enfatiza elementos, tais como: integração das experiências passadas, desenvolvimento de um sentido de individualidade e consciência crescente do próprio destino (GALLATIN, 1978). Na teoria do desenvolvimento de ERIKSON (1976), a tarefa principal do adolescente é construir um sentido do "Eu" (identidade), encaminhando-se para a resolução de seu papel sexual e ocupacional. Assim, suas avaliações e escolhas dependerão da sua adesão a algum papel específico e a uma ideologia.

Para BARBOSA (1987), a adolescência ainda é definida como uma fase da vida em que a pessoa encontra-se num processo constante de desestruturação e reestruturação, cujo ponto central é a elaboração dos lutos com características bastante específicas. De um lado, isso ocorre em função das aquisições progressivas da personalidade, em todos os seus níveis e, de outro, em função dos antecedentes histórico-genéticos e do meio familiar e social em que este processo se desenvolve. Nesta fase o grupo passa a exercer uma grande função modeladora, e o que ele determinar será aceito sem muita reflexão.

Entendemos a importância do adolescente possa experimentar uma multiplicidade de identificações, as quais podem ser bastante contraditórias entre elas mesmas (RASPANTI, 2002). Essa instabilidade é esperada e até mesmo desejada, porém cabe a seu meio ambiente, em especial aos profissionais de saúde, estabelecer limites e orientar esse processo investigativo, para que ele transcorra com segurança, sem causar prejuízos permanentes à sua saúde, como exemplo: uma gravidez indesejada, a exposição a uma situação violenta, uso excessivo de drogas, dentre outros. Ademais, neste momento de vida, o adulto é peça essencial, por influenciar e ajudar o adolescente de maneira construtiva a adquirir limites, que precisam ser continuadamente redefinidos, questionados e testados, uma vez que, na busca de sua função social, o adolescente tenta desenvolver também um novo papel dentro de sua própria família (GAUDERER, 1986a, b e c).

Diante todos estes aspectos optou-se por desenvolver um estudo bibliográfico tendo como tema central o uso de máscaras e dança no sociodrama Moreniano, no atendimento ao adolescente em crise, mais especificamente os recém ingressos na graduação em Enfermagem de Universidades públicas. Isto porque, este grupo geralmente traz consigo, ao serem admitidos na Universidade, o medo de encontrar situações difíceis e não saberem lidar com elas.

\section{OBJETIVO}

Oferecer subsídios para reflexão, articulando a utilização do sociodrama Moreniano utilizando-se de técnicas de dança e confecção de máscaras, em atenção ao adolescente em situação de crise, especificamente aqueles recém ingressos na graduação em enfermagem nas Universidades públicas que, normalmente, trazem consigo o medo de encontrar situações difíceis.

\section{METODOLOGIA}

O estudo caracteriza-se pela busca em livros, dissertações, teses e artigos de revistas científicas; de posse do material, leu-o, elaborando-se a seguir sínteses, descrições, reflexões e articulações sobre os temas abordados como adolescente em situação de crise, sociodrama, máscara e dança terapêutica.

\section{O PSICODRAMA/SOCIODRAMA MORENIANO}

O Psicodrama, então conhecido como Psicologia do Encontro, é uma técnica criada pelo psiquiatra Jacob Levy Moreno (1889-1974), em 1921, que privilegia o encontro consigo mesmo através da relação com-o-outro e a ação, em detrimento das palavras. Fazendo um paralelo deste com a dança e a máscara, percebe-se que as mesmas proporcionam, como o Psicodrama, a ação por meio do encontro não-verbal.

Da ação dramática do psicodrama emergem a ambigüidade e a contradição, que favorecem o desvelar do inconsciente e o transformar consciente, contribuindo para a evolução dos adolescentes, por exemplo, em situação de crise nesse. No Psicodrama, evita-se a causalidade reducionista da compreensão dos 
VALLADARES, Ana Cláudia A.; AVANCI, Rita C.; ABRÃO; Ana Carla P.; PEDRÃO, Luiz J.; LUIS, Margarita A. V.; SOARES, Fernando Carlos107 - Reflexão teórica sobre a utilização da dança e da máscara no sociodrama moreniano com adolescentes em situação de crise. Revista Eletrônica de Enfermagem, v. 07, n. 01, p. 105 - 112, 2005. Disponível em www.fen.ufg.br/revista.htm

fenômenos, com maior destaque à ação prospectiva das atitudes, isto é, ao aqui-e-agora, com o-fazer-e-o-pensar sobre o que foi ou o que está sendo realizado. Ele atua principalmente nas causas e na interpretação dos fatos, dando importância às imagens e demais formas de expressão simbólica do ser humano, como por exemplo, a expressão corporal, as cenas, os silêncios e as expressões artísticas, privilegiando o tratamento e a interação dos adolescentes no grupo.

O sociodrama, tipo especial de intervenção, tem como foco um dado grupo. Nele, considera-se como protagonista sempre o próprio grupo que está sendo investigado, privilegiando o tipo de grupo social ao qual o mesmo pertence. Há distinção entre psicodrama e sociodrama, visto que no primeiro, o sujeito é o indivíduo que sofre, e nele priorizam-se os aspectos individuais. No segundo, o sujeito é o grupo, e a preocupação é o sofrimento de uma coletividade (MORENO, 1994).

O sujeito no psicodrama/sociodrama é um ser em relação, que se forma por meio de seus vínculos, inserido em um contexto sócio-histórico, político-social e psicológico (RAMALHO, 2002). Essas técnicas buscam explorar a vida criativa e espontânea latente no ser humano, visando à obtenção da saúde e à busca da espontaneidade, da autodeterminação e da responsabilidade. Acredita-se que o homem encontra-se em constante desenvolvimento e transformação, e o objetivo do psicodrama/sociodrama é prepará-lo para desenvolver seu potencial espontâneo e criativo em detrimento da submissão das Conservas Culturais, tidas como grandes causadoras da repressão, especialmente da criatividade do adolescente no processo pedagógico.

A espontaneidade, concebida como a capacidade natural do indivíduo, possibilita a este responder adequadamente às diferentes situações com que se depara (OLIVEIRA, 1978). Deve ser liberada em cada situação vivida, pois é considerada elemento catalisador da criatividade, proporcionando realização humana máxima.

A Espontaneidade é definida como a capacidade de responder de forma nova às situações antigas. Espontaneidade, criatividade e sensibilidade seriam recursos inatos do homem, que desde o início, estariam acompanhados tanto de fatores favoráveis ao seu desenvolvimento, quanto de tendências destrutivas. Entre as últimas tendências estariam as Conservas Culturais (RAMALHO, 2002, p. 38).

As Conservas Culturais são padrões comportamentais estereotipados, com valores e formas predeterminados de participação na vida social, que geram a automatização do ser humano, além de se constituírem em obstáculo natural à espontaneidade. As Conservas Culturais são definidas como aspectos "sacralizados" da cultura, guardados zelosamente (OLIVEIRA, 1978). E como o indivíduo adolescente vive num mundo no qual, conhecimentos, valores, tradições são continuadamente questionados em face de novas realidades, essa "conserva" pode não lhe dar os elementos que necessita para se ajustar às novas e difíceis situações. Nesse sentido, o psicodrama/sociodrama, a dança e a máscara trabalharão com essas conservas, ajudando o adolescente a desempenhar seu papel de modo mais pleno e criativo.

$\mathrm{Na}$ Teoria dos Papéis do Psicodrama, procura-se acabar com os papéis artificiais desempenhados no teatro convencional, insistindo com os atores para que abandonassem suas máscaras e apresentassem seu verdadeiro ser (RAMALHO, 2002). Dentro da concepção moreniana, o termo papel recebe dois enfoques: um individual, quando conceituado como "forma real" e tangível, que toma a pessoa, e outro social, significando "unidade cultural da conduta". No primeiro enfoque, o papel está definido como comportamento expresso pelo indivíduo, e é o aspecto interpretação que está sendo enfatizado. Já no segundo enfoque, o papel refere-se ao elemento percepção, isto é, às expectativas associadas ao desempenho que cada adolescente tem do seu mundo. De acordo com OLIVEIRA (1978), ambos os enfoques complementam-se, uma vez que interpretação e percepção são componentes dos papéis que esta população desempenhará.

Dentro da teoria do Psicodrama/Sociodrama, o "Eu" é estruturado com base em papéis psicodramáticos/sociodramáticos, sociais e psicológicos, que se desenvolvem dentro de uma Cena, na qual ocorrem a transformação e a ação ideológica da investigação do Inconsciente. Os papéis psicossomáticos/sociodramáticos ligam-se a funções fisiológicas do indivíduo adolescente, permitindo que este se ligue ao ambiente em que convive. Tais papéis surgem das atividades mentais criadas por situações vivenciadas e às vezes não resolvidas, como exemplo: brincadeiras infantis, faz-de-conta, preparando a criança para assumir papéis sociais no futuro, e poderão corresponder às funções sociais assumidas pelo indivíduo.

O "Eu" é o resultado da co-construção com o grupo do átomo social e se manifesta por meio dos papéis que a pessoa desempenha. Muitos destes papéis são sociais e juntos formam um átomo social. O agrupamento de vários átomos sociais estabelece a rede sociométrica, sendo que os vínculos dessa rede funcionam como uma grande energia, que se transforma a cada momento. Uma outra base fundamental do Psicodrama/Sociodrama é o Fator Tele, vivenciado pelos adolescentes, em uma situação de crise, por exemplo:

Moreira definiu a Tele como a capacidade de se perceber, de forma objetiva, o que ocorre nas situações e o que se passa entre as pessoas. Ou ainda, seria a empatia ocorrendo em duas direções. É o fator télico que permite que o Encontro moreniano aconteça. Esse Encontro, por sua vez, é muito mais que uma 
VALLADARES, Ana Cláudia A.; AVANCI, Rita C.; ABRÃO; Ana Carla P.; PEDRÃO, Luiz J.; LUIS, Margarita A. V.; SOARES, Fernando Carlos 108 - Reflexão teórica sobre a utilização da dança e da máscara no sociodrama moreniano com adolescentes em situação de crise. Revista Eletrônica de Enfermagem, v. 07, n. 01, p. 105 - 112, 2005. Disponível em www.fen.ufg.br/revista.htm

simples reunião entre duas pessoas, é uma experiência privilegiada, um momento de plena compreensão mútua (RAMALHO, 2002, p. 41).

Esse momento da compreensão mútua ocorre pela ligação estabelecida entre um indivíduo e os elementos do meio, com base nas percepções que os adolescentes têm desses elementos. Essa percepção correta, não distorcida da realidade, alicerça-se em atributos reais do indivíduo (OLIVEIRA, 1978). Tem-se que a relação estabelecida por meio da Tele leva à Matriz de Identidade.

A Matriz de Identidade constitui "a placenta social" que nutri o indivíduo por meio da qual o adolescente aprende normas, valores e emoções ligados aos papéis, podendo ser manifestados durante 0 trabalho psicodramático/sociodramático por várias formas de expressão, com a utilização da dança e a confecção de máscaras. Essa matriz, de acordo com OLIVEIRA (1978), transmite ao adolescente em situação de crise a herança cultural do grupo a que pertence e fornece as condições para contínuas reformulações de seus papéis. Esse processo pode facilitar o estabelecimento de vínculos entre os elementos do grupo.

Dentro da teoria Psicodramática/Sociodramática, a matriz de identidade é dividida em dois universos: o da Identidade Total Indiferenciada, evidenciado quando a criança não distingue pessoas de objetos, nem fantasia de realidade. No outro, período de Identidade Total Diferenciada ou Realidade, a criança diferencia pessoas de objetos, o que é real do imaginário e o "Eu" e o "Tu", acrescidos de papéis sociais e psicodramáticos/sociodramáticas.

RAMALHO (2002) refere que esse processo culmina com a adoção de Matriz Social que possibilita maior capacitação para estabelecer vínculos télicos, para inverter papéis com autenticidade e vivenciar Encontros Existenciais. O Psicodrama/Sociodrama trabalha com cinco instrumentos clássicos e, em geral, tem três etapas a cumprir.

Quanto aos instrumentos:

- O Protagonista, que traz o tema para o grupo;

- O Cenário ou o Palco: espaço onde se desenrola o drama, considerado um espaço simbólico;

- O Diretor: que é o psicoterapeuta;

- O Ego-auxiliar: que é um outro terapeuta que trabalha a co-direção, ou em unidade funcional com o diretor;

- O Público ou Platéia: grupo presente na sessão.

As etapas da sessão psicodramática/sociodramática são:

- O Aquecimento: que pode ser específico ou inespecífico. O inespecífico objetiva situar o paciente na sessão, enfatizando sua atenção para si mesmo e favorecendo sua entrada nas novas cenas da sessão; entrada que pode ser verbal ou em movimento (caminhar, alongar, massagear, respirar, usar os jogos dramáticos). O específico acontece após o inespecífico, com um protagonista escolhido pelo grupo, e focalizando sobre o tema emergente.

- A Dramatização, propriamente dita: pode ser feita em cena aberta (Dramatização Internalizada) e mediante um Psicodrama Interno. A Dramatização Internalizada deve ocorrer no cenário no qual acontecem a ação, a definição do tempo, a colocação dos personagens envolvidos, bem como a interação entre estes. No psicodrama interno não existe cenário, o paciente é guiado por suas fantasias espontâneas;

- O Compartilhar: permite que o paciente traga para a ação algo que aconteceu, que gostaria que tivesse acontecido ou, ainda, que queira modificar. $\mathrm{O}$ compartilhar objetiva também a exposição verbal dos sentimentos sobre o que foi vivenciado;

- Os Comentários: referem-se à reflexão intelectual do grupo enfocando a peça trabalhada.

De acordo com as respostas dos sujeitos, podemse utilizar, ainda, as seguintes técnicas Psicodramatistas/Sociodramatistas:

- Técnica do Duplo: quando o terapeuta assume o papel do paciente e mostra o que percebe através de verbalização posterior ao processo;

- Técnica do Espelho: quando o terapeuta ou o ego-auxiliar coloca-se em determinada postura física, reproduzindo a ação feita pelo paciente em algum momento, para que este tome consciência de seus atos;

- Técnica de Inversão de Papéis: o paciente vivencia o papel do outro, gerando um distanciamento que favorece a tomada de consciência dos fatos;

- Auto-apresentação: apresentação da pessoa em relação aos seus diversos papéis desempenhados na vida;

- Apresentação do átomo social: quando o paciente apresenta seu mundo referenciado a partir do seu mundo subjetivo;

- Solilóquio: equivale à expressão verbal dos sentimentos e pensamentos secretos da dramatização, manifestada através de diálogos e ações separados;

- Interpolação de resistência: contraria aspectos conscientes, rígidos e temidos pelo protagonista;

- Concretização: significa a representação psicodramática/sociodramática auxiliada por objetos inanimados (máscaras, objetos, obras de arte, entre outros);

- Realidade suplementar: expressão do mundo real e da fantasia da pessoa envolvida, representada através da ação dramática.

RAMALHO (2002) expõe que o benefício terapêutico do Psicodrama/Sociodrama moreniano só existe quando não apenas se repetem os conflitos básicos, mas quando são revivenciados no aqui-e-agora, diferenciando-os, partindo para a re-criação de um papel (que foi cristalizado em sua espontaneidade, no passado). A Catarse de Integração possibilita a catarse do ator e do criador (transforma cada sujeito).

Mas será que o sociodrama é uma técnica que pode ser empregada com adolescentes em situação de 


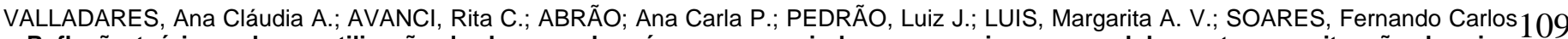
- Reflexão teórica sobre a utilização da dança e da máscara no sociodrama moreniano com adolescentes em situação de crise. Revista Eletrônica de Enfermagem, v. 07, n. 01, p. 105 - 112, 2005. Disponível em www.fen.ufg.br/revista.htm

crise? Será que o uso da máscara e da dança possibilitariam um tratamento terapêutico favorável a esta clientela? Percebe-se que esta preocupação reflete desafios da atuação dos profissionais de enfermagem, emergindo daí a necessidade de uso de outros tipos de terapias baseadas na arte, teatro, dança entre outras, como práticas complementares e criativas no processo de melhorar a qualidade de vida dos adolescentes em situação de crise.

\section{A UTILIZAÇÃO DA DANÇA E DA MÁSCARA NO SOCIODRAMA MORENIANO COM ADOLESCENTES EM SITUAÇÃO DE CRISE}

As máscaras são o registro vivo da história da humanidade. Suas primeiras manifestações surgiram na pré-história juntamente com a existência humana. Originalmente, elas tinham um aspecto mágico, eram feitas de peles de animais, e quando usadas pelo homem primitivo, camuflavam o caçador, atraindo ou matando suas presas.

A máscara, segundo LEXIKON (1994), é uma forma expressiva bastante antiga, usada constantemente para encobrir o rosto, com a finalidade de assustar os inimigos. Em práticas mágicas, representavam os espíritos e poderes personificados de animais e homens, acentuando quase sempre, de maneira evidente, determinados traços estereotipados do caráter. Deduz-se, então, que as máscaras sempre estiveram presentes em todas as culturas, como manifestações de costumes, religiões e de outros temas ligados à vida do ser humano e à história da humanidade, ora a serviço da vida cotidiana, como instrumento de uma técnica mágica ou como continuação da realidade; ora representando algo profano, sagrado ou espantando os maus espíritos, ora ainda representando algo apenas decorativo (VALLADARES et al., 2000). Na dança, a máscara é freqüentemente utilizada, como exemplo, o ballet de repertório El amor brujo.

Conforme BUCHBINDER (1996), a máscara não é privativa do homem primitivo; pertence também à cultura atual de diferentes modos, pois se acredita que o uso da mesma pelo indivíduo contemporâneo resulte na possibilidade de se trabalhar terapeuticamente com ela, permitindo-lhe, em especial ao adolescente, expor sua história universal, pessoal e mitológica.

Dentre os vários recursos expressivos usados no Psicodrama/Sociodrama, este estudo pretende fazer uma articulação do uso das máscaras e da dança terapêutica dentro da técnica sociodramática com adolescentes em situação de crise. A máscara é um objeto fascinante para todos, que disfarça, simula e transforma, além de permitir a libertação de sentimentos que jamais seriam exteriorizados em uma aula tradicional. A máscara possui, ainda, uma carga simbólica muito evidente, que estimula a fantasia, a criação e a imaginação, devido ao seu aspecto lúdico e criativo (VALLADARES, 2001).

Para CHEVALIER \& GHEERBRANT (2003), a máscara pode ser definida como uma cobertura, um disfarce, colocado sobre o rosto para dissimulá-lo ou substituí-lo por um outro artificial, criando assim a ilusão. A máscara representa o estado rudimentar da consciência, no qual não há distinção absoluta entre ser e parecer e em que a modificação da aparência determina a modificação da própria essência.

Assim, a introdução da confecção de máscaras no Sociodrama, com suas inúmeras possibilidades, fará surgir elementos do conteúdo intrapsíquico necessários à compreensão e transformação grupal, facilitando o relacionamento do grupo. Nessas circunstâncias, o Sociodrama não utilizará a máscara apenas como recurso teatral, educacional ou como forma de divertir ou distrair, mas especialmente como forma de expressar conteúdos internos conflitantes dos adolescentes em situação de crise, a fim de resgatar o ajustamento emocional desta população.

A função terapêutica da máscara é seu aspecto desmascarante, de desestruturação e, posteriormente, reestruturante do sujeito, isto é, possui um caráter expressivo e energético bastante intenso. O fenômeno de desestruturação ocorre quando uma pessoa coloca uma máscara e imediatamente surge o desmascaramento de outros aspectos inerentes a ela (BUCHBINDER, 1996).

Tanto a dança, assim como a dramatização, facilitam a expansão do território interior do adolescente em situação de crise, auxiliando-o no estabelecimento de vínculos da rede sociométrica pelo agrupamento dos átomos sociais desta população em movimento de energia viva.

A máscara, juntamente com a dança podem minimizar os conflitos advindos dos personagens internos do intrapsíquico, dificultando a transferência e a ausência da tele (fundamento de todas as relações interpessoais sadias, percepção do que se passa com as pessoas em seu meio).

A linguagem do movimento corporal da dança inclui movimentos criadores que estimulam a atividade mental. Para PETO (2000), a dança viabiliza a capacidade de dar respostas novas, criativas e adequadas a situações inesperadas, além de fazer florescer no adolescente a espontaneidade, tornando-o mais apto a enfrentar a vida.

Tanto a confecção de máscaras como a dança, investigam vínculos, trazem insights reveladores e extrapolam o verbal, utilizando o corpo e a ação, a expressão e a interação para desbloqueio da energia espontânea, desenvolvimento da tele e fortalecimento das relações sadias. Ações que ao serem desenvolvidas no grupo (sociodrama) com adolescentes em situação de crise provocam e abrem novas possibilidades, permitindo trabalhar a tolerância, a paciência; o aprender a ouvir, a falar e a interagir, fatores que possibilitam aos 
VALLADARES, Ana Cláudia A.; AVANCI, Rita C.; ABRÃO; Ana Carla P.; PEDRÃO, Luiz J.; LUIS, Margarita A. V.; SOARES, Fernando Carlos 110 - Reflexão teórica sobre a utilização da dança e da máscara no sociodrama moreniano com adolescentes em situação de crise. Revista Eletrônica de Enfermagem, v. 07, n. 01, p. 105 - 112, 2005. Disponível em www.fen.ufg.br/revista.htm

participantes a conquista de um clima de confiança e de ajuda mútua. A partir de trocas subjetivas, criam uma atmosfera de liberdade na qual o grupo irá fluir como um fenômeno, fixando a valorização da abordagem moreniana para o conhecimento e compreensão do fenômeno.

Outro fator importante é o prazer dos adolescentes frente ao oferecimento de um espaço no qual eles possam fluir com naturalidade. A tele permite que uma mútua sensibilidade uma os adolescentes, favorecendo seu crescimento, espontaneidade e criatividade.

CALVENTE (2005), ao realizar suas sessões de psicodrama com um adolescente, percebeu que através da matriz de identidade pôde conhecer o clima em que vivia seu paciente. Assim, o resto da família pôde ter uma idéia mais real do terapeuta e da terapia, contribuindo para desmistificá-lo e para preparar um campo mais relaxado para o paciente. $\mathrm{O}$ autor concluiu que, quanto menos o adolescente for afastado de seu meio, maior será o entendimento de seus tropeços e dificuldades e melhores serão as condições para ajudálo.

A adolescência é uma fase importante para a estruturação do indivíduo e a família. Nesta etapa, ocorrem transformações importantes na vida da pessoa. O adolescente, especificamente na situação de crise, significa o aparecimento de algum acontecimento não esperado em sua vida que acarreta danos psíquicos em sua vida que deverão ser trabalhados almejando uma adaptação ao seu novo estilo de vida. Os alunos adolescentes que, por exemplo, ingressam nas universidades públicas continuarão provavelmente a apresentar características típicas da fase, como ansiedades, inseguranças e conflitos internos, dificultando, conseqüentemente, o seu desenvolvimento normal e desempenho escolar. Para esses adolescentes no início do curso de graduação em enfermagem nas Universidades públicas normalmente trazem consigo, além das características da própria fase já citadas anteriormente, o medo de se depararem com situações difíceis, como rejeição pelo grupo nessa nova etapa de suas vidas. Muitos deles deixam suas famílias e, como cidadãos, partem em buscar de nova formação profissional, e as dificuldades encontradas poderão prejudicar tanto seu processo educacional como o relacionamento e os aspectos emocionais. Conseqüentemente, alunos adolescentes que recentemente ingressam no curso de graduação em enfermagem nas universidades públicas podem se caracterizar por uma situação de crise e são objeto deste estudo.

Visando amenizar essa situação de crise, considera-se importante a realização de atividades sociodramáticas associadas à dança e à máscara com esses adolescentes iniciantes do curso de graduação em enfermagem, a fim de auxiliá-los à fornecer o vínculo e a sua integração grupal, facilitando o processo pedagógico. Acredita-se que o uso desses recursos desenvolva a expressão e a imaginação espontâneas, favorecendo a descarga das tensões e a exteriorização de suas alegrias, temores e fantasias.

O sociodrama pedagógico pode ser utilizado como instrumento, enquanto a dança e a máscara constituemse nos objetos de situações intermediárias para o aquecimento específico, os quais levarão ao desenvolvimento de vínculos e de tele-relação, impedindo o surgimento de situações transferenciais.

Nessa perspectiva, as sessões de sociodrama favorecerão a diminuição das ansiedades e inseguranças desses jovens, permitindo que compartilhem seus sentimentos e emoções com os colegas, de maneira mais profícua. Assim, o sociodrama junto a esta clientela, em uma situação de crise, poderá ajudá-lo a enfrentar com maior naturalidade suas dificuldades e encontrar sua identidade e sua autonomia.

\section{CONSIDERAÇÕES FINAIS}

Frente ao exposto, das reflexões levantadas considera-se que o trabalho do psicodrama/sociodrama junto aos adolescentes em situação de crise torna-se importante para amenizar os efeitos negativos deste processo que tanto ameaçam o seu desenvolvimento normal. Esses dados confirmam os resultados dos estudos realizados com adolescentes utilizando-se técnicas terapêuticas não-verbais de VALLADARES \& NOVATO (2001) e RASPANTI (2002), ambos realizados em escolas de Goiânia (GO) e Ribeirão Preto (SP), respectivamente. VALLADARES \& NOVATO (2001) após realizar um trabalho de arteterapia com adolescentes de uma escola pública de Goiânia/GO demonstrou que o uso desta modalidade terapêutica possibilitou mudanças comportamentais positivas nos adolescentes revelados pela diminuição da ansiedade, insegurança e melhoria e integração grupal. Em sua pesquisa, RASPANTI (2002) estabeleceu cinco encontros com abordagem de diversos temas (drogas, gravidez, AIDS etc), utilizando a metodologia psicodramática, tendo, como população, adolescentes de uma escola de $1^{\circ}$ grau de Ribeirão Preto/SP. Os resultados levaram a autora a perceber que os participantes do grupo apresentaram mudanças no comportamento diversas e permitindo melhor interação do grupo.

Os autores sinalizam que, ao possibilitarem o contato dos adolescentes em situação de crise com técnicas não-verbais e de forma mais lúdica, no qual esta clientela possa se expressar de maneira mais natural e espontânea, sendo assim menos agressiva, como o uso de máscaras e dança, que permitem fazer articulações positivas. Dado que vai também de encontro com a pesquisa de arteterapia realizada por VALLADARES (2004) com crianças internadas em um hospital público de Goiânia (GO), no qual beneficiaram as crianças, em situação de estresse e crise - como a 
hospitalização, a doença e o tratamento invasivo. Esta técnica terapêutica, a arteterapia, que tem um enfoque predominantemente não-verbal, permitiu a seus participantes experimentarem novos papéis, desenvolverem seu potencial criativo, sua autoexpressão, sua imagem negativa e sua autonomia, além de favorecer a canalização de tensões, a exteriorização mais espontânea de sentimentos, emoções e comunicação de pensamentos. Assim, a uso de condutas lúdicas, como a dança e a confecção de máscaras, dentre de um processo terapêutico do sociodrama/psicodrama em muito favoreceriam o adolescente a se expressar, criar e estabelecer relações com o mundo, facilitando vivenciar de forma menos sofrida e angustiante $\mathrm{o}$ ingresso na Universidade pública.

Enfim, o sociodrama, utilizando-se de técnicas de confecção da máscara e da dança possibilitaria maior liberdade na expressão das emoções, criaria oportunidades que levem os adolescentes a aceitar com mais naturalidade as situações desfavoráveis e diminuindo as situações de estresse.

Espera-se, com este estudo, ter contribuído para o avanço do conhecimento na área da enfermagem ou da saúde mental, em geral, permitindo o uso de terapêuticas alternativas e criativas que favoreçam de maneira espontânea o adolescente trabalhar seu lado emocional favorecendo sua saúde mental.

\section{REFERÊNCIAS BIBLIOGRÁFICAS}

ABEN. Adolescer: compreender, atuar, acolher: Projeto Acolher. Brasília: ABEN, 2001.

ABERASTURY, A.; KNOBEL, M. Adolescência normal: um enfoque psicanalítico. Porto Alegre, Artmed, 2000.

BARBOSA, L. H. S. Depressão na infância e na adolescência. Aspectos sociais. Cad. Saúde Pública. Rio de Janeiro, v. 3, p. 250-265, 1987.

BECKER, D. O que é adolescência. 10. ed. São Paulo: Brasiliense, 1994.

BUCHBINDER, M. A poética do desmascaramento: os caminhos da cura. São Paulo: Ágora, 1996.

CALVENTE, C. F. Psicodrama em adolescentes. In BUSTOS, D. M. (org.). O psicodrama: aplicações da técnica psicodramática. 3. ed. São Paulo: Ágora, p.193-197, 2005.

CHEVALIER, J.; GHEERBRANT, A. Dicionário de símbolos. 11. ed. Rio de Janeiro: José Olympio, 2003.

ERIKSON, E. H. Identidade, juventude e crise. Rio de Janeiro: Zahar, 1976.
GALLATIN, J. E. Adolescência e individualidade: uma abordagem conceitual da psicologia da adolescência. São Paulo: Harbra, 1978.

GAUDERER, E. C. Adolescência, os jovens e nós: uma visão pessoal. 2. parte. Um ser esquisito. J. Pediatr, São Paulo, n. 6, p. 132-150, 1986a.

GAUDERER, E. C. Adolescência, os jovens e nós: uma visão pessoal. 3. parte. Um ser em perigo. J. Pediatr, São Paulo, n. 6, p. 213-218, 1986b.

GAUDERER, E. C. Adolescência, os jovens e nós: uma visão pessoal. 4. parte. Um ser amável. J. Pediatr. São Paulo, n. 6, p. 337-346, 1986c.

LEXIKON, H. Dicionário de símbolos. São Paulo: Cultrix, 1994.

MORENO, J. L. Psicodrama. São Paulo: Cultrix, 1994.

OLIVEIRA, Z. M. R. Educação da espontaneidade: uma perspectiva na formação de professores. 1978. 102p. Dissertação (Mestrado) - PUC, São Paulo.

PETO, A. C. Terapia através da dança com laringectomizados. Relato de experiência. Rev. Latino Am. Enfermagem, Ribeirão Preto, v.23, n. 6, p.110-113, jul-set, 2000.

RAMALHO, C. M. R. Aproximações entre Jung e Moreno. São Paulo: Ágora, 2002.

RASPANTI, L. M. P. S. Trabalho com grupo de adolescentes através da abordagem sociodramática. 2002. 112p. Dissertação (Mestrado) - Escola de Enfermagem de Ribeirão Preto, Universidade de São Paulo, Ribeirão Preto.

VALLADARES, A. C. A. A máscara como recurso expressivo de doentes com AIDS e de profissionais/estudantes da saúde. In: Rev. Imagens da Transformação, v.8, n. 8, p. 05-15, set, 2001.

VALLADARES, A. C. A. Manejo arteterapêutico no préoperatório em pediatria. Rev. Eletrônica de Enfermagem [online], Goiânia: UFG, v.6, n.1, p.110-115, 2004. Disponível: http://www.fen.ufg.br/revistal [acesso em 18 jul. 2005].

VALLADARES, A. C. A. et al. A máscara como recurso expressivo de crianças hospitalizadas. In MENDES, I. A. C.; CARVALHO, E. C. (org.). Comunicação como meio de promover saúde. $7^{\circ}$ Simpósio Brasileiro de Comunicação em Enfermagem. Ribeirão Preto: Fundação Instituto de Enfermagem de Ribeirão Preto, p.197-201, 2000.

VALLADARES, A. C. A.; NOVATO, A. C. R. S. Aspectos transformadores da construção em arteterapia com adolescentes. Goiânia: Rev. Eletrônica de Enfermagem [online], Goiânia: UFG, v.1, n.3, 2001. Disponível: http://www.fen.ufg.br/revista [acesso em 18 jul. 2005]. 
VALLADARES, Ana Cláudia A.; AVANCI, Rita C.; ABRÃO; Ana Carla P.; PEDRÃO, Luiz J.; LUIS, Margarita A. V.; SOARES, Fernando Carlos112 - Reflexão teórica sobre a utilização da dança e da máscara no sociodrama moreniano com adolescentes em situação de crise. Revista Eletrônica de Enfermagem, v. 07, n. 01, p. 105 - 112, 2005. Disponível em www.fen.ufg.br/revista.htm

${ }^{1}$ Enfermeira e Arteterapeuta, Profa Assistente da Faculdade de Enfermagem da Universidade Federal de Goiás (FEN/UFG) e Doutoranda do Programa de Pós-graduação em Enfermagem Psiquiátrica pela Escola de Enfermagem de Ribeirão Preto da Universidade de São Paulo (EERP/USP). FEN/UFG - Rua 227 Qd. 68 s/no Setor Leste Universitário. Goiânia/Go CEP: 74.605-080 - Fax: (62) 521-1807 E-mail: aclaudiaval@terra.com.br

${ }^{2}$ Enfermeira, Meste pelo Programa de Pós-graduação em Enfermagem Psiquiátrica pela EERP/USP; ${ }^{3}$ Profo ${ }^{\circ}$ Dr $^{\circ}$ do Departamento de Enfermagem Psiquiátrica e Ciências Humanas da EERP/USP

${ }^{3} \mathrm{Prof}^{\mathrm{a}} \mathrm{Dr}^{\mathrm{a}}$ do Departamento de Enfermagem Psiquiátrica e Ciências Humanas da EERP/USP

${ }^{4}$ Profo $^{\circ} \mathrm{Dr}^{0}$ do Departamento de Pediatria de Faculdade de Medicina de Ribeirão Preto da USP

Texto original recebido em 14/11/2004

Publicação aprovada em 30/04/2005 